\title{
La promesa del minotauro
}

\author{
Rafael Chico Quintana ${ }^{1}$ \\ Universidad de Cartagena
}

\begin{abstract}
"El Minotauro triunfa y su laberinto habita todas las almas. Desde ahora y por siempre él llegará antes que todos y todas, estará en medio de nuestros deseos, corneará todos los tronos y colocará en cada corazón un laberinto diminuto y terrible".
\end{abstract}

Carlos Oliva Mendoza, "Deseo y mirada del laberinto".

\section{Resumen}

El presente ensayo se centra en el análisis de la escisión del personaje protagonista del cuento "Cuello de gatito negro", de Julio Cortázar, Dina, en dos entidades que encarnan las tramas discursivas de dos ontologías mutuamente excluyentes: el esencialismo racionalista de Platón y Descartes, y el existencialismo erótico de corte marcuseano (Eros y civilización) y nietzscheano (la visión dionisiaca), con el fin de describir la propuesta ontológica del mismo cuento. El decurso expositivo del artículo se ve obligado a transitar por un conjunto de motivos y símbolos caros al universo cortazariano, pero ello con el afán de franquear el camino hacia esa dilucidación de la propuesta del relato.

Palabras clave: arquetipo, Minotauro, esencialismo racionalista, dionisíaco, condición fragmentaria

\section{Abstract}

The present enssay is centered in the analysis of the protagonist personage split in Julio Cortázar's story, Neck of black kitten, (Cuello de Gatito Negro) Dina, in two entities that incarnate the discursive plots of two mutually excluding ontologies: the rationalist essentialism of Plato and Descartes, and the erotic existentialism of Marcusean's (Eros and civilization) and Nietzschean's (the Dionysius vision) influences, with the purpose of describing the ontological proposal of the same story. The Expositve course of the article is forced to journey by a set of reasons and symbols expensive to Cortazar's universe, but that with the eagerness to cross the way towards that elucidation of the story proposal.

Key words: archetype, Minotaur, rationalist essentialism, Dionysus' fragmentary condition

\footnotetext{
${ }^{1}$ Egresado del Programa de Lingüística y Literatura de la Facultad de Ciencias Humanas de la Universidad de Cartagena. El presente ensayo hace parte del trabajo de grado "El Yo, la negación del cuerpo y la derrota", Cartagena, 2006. E-mail: rafachicoquintana@yahoo.es
} 
El motivo de la disyuntiva trágica ("la doble hacha") es retomado en varias de las obras de Julio Cortázar, y en Los reyes cristaliza en forma más perfecta, arrojando destellos que esclarecen obras posteriores. En esencia, dicho motivo se relaciona con una de sus más queridas obsesiones, la noción de laberinto. Consigna Luis Harss, a propósito de ello:

Sin embargo, el libro [Los reyes] introduce una imagen que aparece repetidamente en la obra de Cortázar: el laberinto. Aquí es sólo fachada y enroscadura. Pero hay un Cortázar que atribuye un significado más profundo a este símbolo arquetípico. Sabe menos que nadie, dice, que oscuras fuentes biográficas -o reminencias literarias- se ocultan en la raíz de este fenómeno, en el que descubre restos de un ritual infantil. Recuerda que "desde niño todo lo que tuviera vinculación con un laberinto me resultaba fascinador. Creo que eso se refleja en mucho de lo que llevo escrito. De pequeño fabricaba laberintos en el jardín de mi casa. Me los proponía" (el destacado es nuestro). (Harss, 1969: 265).

Sobre este motivo, Oliva Mendoza ha profundizado en la novela más popular del autor, Rayuela. Dice:

De todas ellas la imagen que encontramos en Rayuela es la del laberinto; pero nuestra imagen no es mitológica o inmóvil. Por el contrario, el laberinto que figura Cortázar es un laberinto que se constituye y crea a partir de la propia historia y de un deseo de representación de la realidad que, a la vez, se nos muestra como una forma alcanzada que posibilita el acceso al juicio y a la representación. Nuestro laberinto (latinoamericano) está hecho de historia y tiempo y eso sólo es posible si en el laberinto hay participación del otro y de la otra. (Oliva Mendoza, 2002: 128-129).

Las justas proporciones y complejidades del laberinto han sido descritas por el crítico, sin embargo, pese a que se acepta la interpretación historicista de su tesis, a la vez, se renuncia a ella. La dimensión arquetípica del motivo dentro del contexto del presente trabajo entronca con algo más amplio. Del mismo modo que el laberinto de Los reyes aprisiona a sus protagonistas en disyunción trágica ("la doble hacha"), considero que encierra a los personajes de "Cuello de gatito negro" (1998) de un modo que compromete su condición de modelos humanos y no su adscripción socio-histórica. Como expresión sí de una herencia cultural más amplia, la ontología occidental. Una dimensión existencial que el mismo Oliva Mendoza comenta desde los límites de su horizonte interpretativo: "Cortázar, al volver a contar el mito del Minotauro, ficcionó que Ariadna sabía que el laberinto nos habita, [...]" (2002: 130). Y luego dice: "El Minotauro triunfa y 
su laberinto habita todas las almas. Desde ahora y por siempre él llegará antes que todos y todas, estará en medio de nuestros deseos, corneará todos los tronos y colocará en cada corazón un laberinto diminuto y terrible" (133).

Así es, pero, el extravío es fruto del encierro entre dos deseos, dos sentimientos, dos opciones, la bifurcación hasta el infinito. Todo en torno al centro de las expectativas, y no porque se identifique, como opina Oliva Mendoza, con el laberinto mismo. Tiene razón al afirmar que la narrativa del argentino construye un héroe alrededor del cual giran "el núcleo más importante de respuestas y de la trama", respecto a las cuestiones de para qué y por qué enfrentar al Minotauro; también acerca de que la superabundancia de éstas es responsable de la complejización del encierro (Oliva Mendoza, 2002: 89-90 y 131133). Sin embargo, el Minotauro mismo ofrece la solución al enigma: "Parece que miraras a través de mí. No me ves con tus ojos, no es con los ojos que se enfrenta a los mitos" [El destacado es nuestro] (Cortázar, 1992: 64); "No hay malicia en tus ojos, joven rey. Tan claros que la realidad pasa por ellos y no deja más que apariencias, su arena en el cedazo. Aún no me has domeñado. Y no sabes que muerto seré distinto. Pesaré, Teseo, como una inmensa estatua. Cuernos de mármol se afilaran un día contra tu pecho", y: "Mira, sólo hay un medio para matar los monstruos: aceptarlos" (69 y 71).

Comprensión, aprender a mirar desde dentro, "con tus ojos", entender que eso otro no es el enemigo. En tal estado de cosas, el Minotauro no es la arquitectura del extravío, sino que ésta es la imposibilidad de reconocer la justa imagen de lo erróneamente demonizado. Ahora bien, el caso de Ariadna es diferente, su laberinto sabe a otra materia. En ella el ser oscila entre la actitud correcta y el miedo a perderse entre las galerías, indecisión de dar el paso -sobre ello se hablará más adelante -. En cuanto a Dina, las paredes de su laberinto están hechas del doble fracaso: el ansia espiritualista por despojarse de la carne y volar cual ave platónica al reino inalterable de la esencia, actualizando así el esencialismo racionalista que ha forjado su super-yo, la autoridad que juzga; mientras su corazón atado a tierra lucha furioso por ir al encuentro del próximo abismo de éxtasis que le devuelva incontenible y seguro al estado de plenitud devengado por la anulación que implica el estado dionisiaco². Dos deseos, dos

${ }^{2}$ Según Nietzsche, el estado dionisiaco es el momento revelatorio del esplendor vital de la naturaleza. Rinde ésta su rostro feliz y bondadoso en la forma de la maximización explosiva del placer; la embriaguez y la fiesta de Dionisio son su más concreta representación. En dicho estado, el ser renuncia a su racionalismo, replegándose contento en torno a su condición instintiva, pues el orden natural le retribuye con la desmesura anulante del éxtasis y sólo la posición de receptor libre 
caminos y dos resultados coexistentes e incompatibles, gracias a la escisión en dos macro-entidades mutuamente interferibles: La Voz y La No-voz:

[...] fósforos que la mano de Dina no había querido sostener, que había doblado hacia abajo para quemarse y quemarla (a Dina) [...] pero después del segundo fósforo aplastado entre los dedos, cangrejo rabioso quemándose con tal de destruir la luz entonces Dina había tratado de encender un ultimo fósforo con la otra mano y había sido peor, [...]. No te das cuenta que no quieren [las manos], es otra vez [El destacado es nuestro]. (Cortázar, 1998: 114)

Para La Voz la búsqueda de la luz física es el intento por subsanar la carencia de una condición sin la cual no hay posible redención: el control sobre el cuerpo. Ello porque,desde la óptica del esencialismo, en la escisión cuerpo-alma el acento de la esencia pesa sobre el alma e irremediablemente excluye al cuerpo de una participación efectiva en la composición del ser. De allí la ya larga tradición de considerarle habitáculo de la misma, y en el peor de los casos, su prisión. El cuerpo es, por tanto, seudo-componente del ser, o más propiamente, su estación de paso, ya que, a diferencia del alma, está sujeto a los poderes corrosivos del tiempo y condenado a su más temible consecuencia: la muerte. En el caso de Dina, "No te das cuenta que no quieren", el cuerpo es un dios sobre sí mismo que, además, contraviene, invocando los peligros de la anulación representados por la oscuridad.

Ahora bien, existe una paradoja dramática dentro del mismo juego diarético al que apuesta el esencialismo de La Voz. Siguiendo a Freud, se afirmaría que Dina compensa inconscientemente la necesidad de contacto sexual con la autonomía corporal, debido al gran encomio dado por la autoridad superior (el esencialismo racionalista platónico-cartesiano) al ideal del ente asexual. La necesidad de internalizar lo bueno, o más bien, legitimado, obliga a la muchacha a rechazar la sexualidad sin optar por la renuncia pragmática. El instinto sigue satisfaciéndose con la autonomía, y a la vez, se acata a la autoridad con la autodefinición. La muchacha queda protegida con la proyección de la responsabilidad y la culpa en el sujeto B (La No-voz), a la vez que actualiza los discursos represivos de la autoridad autodefiniéndose como el sujeto A (La Voz). Mas, el precio es

de restricciones morales, sociales y racionales le permiten la experiencia plena. El estado es un contexto de pérdida de la noción de sí o de la individuación-principium individuatinis, dice Nietzsche (1981: 230-255). 
alto, porque el desgarrón del yo, aun cuando aísla la conciencia de la culpa, delínea en Dina la tensión emocional de la antagonía, haciendo sufrir a la muchacha el infierno de verse atrapada y violada en situación de prisión lacerante.

Por otra parte, la caída en la pasión, exigida por La No-voz, no es un juego de tibiezas y titubeos:

La sentía resistir apenas, repetir la negativa en la que había habido como el principio de una prevención, pero todo cedía en ella, en los dos, ahora los dedos de Dina subían lentamente por la espalda de Lucho, su pelo le entraba en los ojos, su olor era un olor sin palabras ni prevenciones, la colcha azul contra sus cuerpos, los dedos obedientes buscando los cierres, dispersando ropas, cumpliendo las ordenes, las suyas y las de Dina contra la piel, entre los muslos, las manos como las bocas y las rodillas y ahora los vientres y las cinturas, un ruego murmurado, una presión resistida, un echarse otras, un instantáneo movimiento para trasladar de la boca a los dedos y de los dedos a los sexos esa espuma que lo allanaba todo, que en un mismo movimiento unía sus cuerpos y los lanzaba al juego [El destacado es nuestro]. (113).

El estado dionisiaco exige la entrega total, y es imposible, porque La No-voz es sólo una porción del ser Dina. "La voz suspendida en algún punto del aire negro" sigue su cuadro de angustias frente a la anulación y se alza como una resistencia, impidiendo la plenitud, aguardando su turno para regresar luego del estado dionisiaco, más reprobatoria y reafirmante de la miseria. Este atrapamiento circular entre galerías distintas, pero conectadas, hace eco de otro atrapamiento más conocido por el lector promedio de Cortázar. Se habla del juego de salto cíclico entre dos capítulos, al final de Rayuela. De por sí, ausencia de fin y atrapamiento de la lectura en el repliegue del texto sobre sí mismo, sin ofrecer respuesta a las expectativas suscitadas en torno al personaje central. Oliveira se muestra en toda su fragmentaria condición. Dina también exhibe su indigencia, su condición fragmentaria, de la cual no se puede extraer imagen diferente a la bifurcación de caracteres excluyentes y ambos con el mismo derecho de esencialidad.

Pero, ¿cuál es el monstruo a aceptar?, ¿cuál su Minotauro? Su instintividad, y por ende, la visión erótica contenida en ella. El divorcio del Minotauro exigido por la autoridad en gran manera es responsable de su demonización y las innegables amenazas que cierne sobre la identidad -no se puede negar que el acto sexual como es propuesto 
por La No-voz entraña consecuencias vejatorias contra la integridad de la muchacha, "Sería mejor que lo otro, que tantas veces. Ninfo no sé cuanto. Putita, tortillera" (111)-. Sin embargo, las promesas de la visión erótica son de igual manera un bien necesario. Presentándose en respuesta al cómo soslayar la doble vía, aviene la respuesta nocturna del otro (Lucho):

La abrazó estrechamente, sin saber de qué o por qué tenía que calmarla, le murmuró palabras de alivio, la tendió contra él, bajo él, la poseyó dulcemente y casi sin deseo desde una larga fatiga, la entró y la remontó sintiéndola crisparse y ceder y abrirse y ahora, ahora, ya, y la resaca devolviéndolos a un descanso boca arriba mirando la nada, oyendo latir la noche con una sangre de lluvia, allí afuera, interminable gran vientre de la noche guardándolos de los miedos, de las barras de metro y lámparas rotas y fósforos que la mano de Dina no había querido sostener, [...]. [El destacado es nuestro]. (114).

Nótese el acto despojado del inductor pasional, "casi sin deseo", impelido desde una semineutralidad erótica por fuerzas emocionales ajenas a la satisfacción egoísta. Instrumentalizado de tal modo que Dina se descosifica al interior de una esfera de valores que le sacan a flote en calidad de legítimo objeto de preocupaciones y cuidado. Sea dignificada entonces en el estatus de ser querido: "la abrazó estrechamente sin saber por qué tenía que calmarla, le murmuró palabras de alivio". El otro obra como ente protector, no un héroe, con todo el resplandor diurno que dicho término arrastra. Se está frente a un ser que comparte semejanzas con el gran arquetipo del resguardo, la madre (Durand, 1982: 215-221). De hecho, el acto sexual: "la poseyó dulcemente", se muestra eufemizado o adscrito al esquema del descenso, en la forma de la penetración en la madre; acción que, tal como dice Durand, no se desvincula de la deglución sexual o digestiva, es decir, bajada al vientre (221). La dulce posesión arrebata al personaje de su trabajosa miseria, "desde una larga fatiga". La traga, "la entró", actuando por tal medio el proceso de gulliverización $n^{3}$. La chica es transportada en el clímax a espacios de tranquilidad redentora: "la remontó". Pero esta "elevación" no es sino lo descrito por Durand, a propósito del pensamiento de Blake: descender para "remontar el tiempo y volver a encontrar la

\footnotetext{
${ }^{3}$ La gulliverización (miniaturización), explica Durand, va asociada a las simbologías de la penetración íntima. Es un retroceder al estado mínimo del feto aislado y protegido por el paraíso nutricio del vientre. En dichos términos se utiliza aquí. (Cf. Durand,1982: 201).
} 
calma prenatal" (193). El vientre como cielo al interior del cual no se ofrece resguardo a una u otra componente del ser de Dina (La Voz o La No-voz), sino la totalidad cual encierro disipador de la antagonía entre la autoridad y la instintividad. El complejo existencial Dina cede y se abre a la vinculación emotiva admitidora de ambas partes, implicadora, a la vez, de la fusión con el otro. Pero tal fusión se diferencia radicalmente de esa otra ocurrente bajo el imperio del estado dionisiaco. Háblase entonces de un clímax eufemizado, pues no se aspira a consumir los actantes en el resplandor temporal de éxtasis, sino a la protección de la gran amenaza: "gran vientre de la noche guardándolos de los miedos, de las barras de metro y lámparas rotas y fósforos que la mano de Dina no había querido sostener".

En buena medida se podría afirmar, estar en presencia de un tipo de anulación de las individualidades -Dina con su yo escindido y Lucho con su otredad- o más bien, la ingerencia del otro se presenta como la irrupción de la mirada (Oliva, 2002: 89-127 y 127-133). La mirada, tal como la define Oliva Mendoza, es orientación en el extravío laberíntico. Incluye al otro, porque "sólo nos queda esperar que en los ojos del otro y de la otra se refleje alguna parte de la imagen del laberinto que nuestra soledad nos impide ver" (133). Ello explica la reiteración del motivo de la pareja en varias obras de Cortázar (Rayuela, "Manuscrito hallado en un bolsillo", "Circe", "La señorita Cora" y otros) como también las secuencias finales de Cuello de gatito negro, donde Lucho suplica por la restauración del vínculo luego de ser expulsado por el gato:

[...], abrime Dina, abrime, no importa que siempre haya sido así pero abrime, éramos otra cosa, Dina, hubiéramos podido encontrar juntos, por qué estás ahí en el suelo, qué te hice yo, por qué te golpeaste contra la puerta, [...] Dina, todavía podemos encontrar la vela, [...], tendré que decirles que estás ahí tirada, [...], que te cuiden y te protejan porque yo ya no estaré ahí, nos separarán enseguida, verás, nos bajarán separados y nos llevarán lejos uno del otro, qué mano buscarás, Dina, qué cara arañarás ahora mientras te llevan entre todos y madame Roger [El destacado es nuestro]. (Cortázar, 1998: 116).

El amor no es la salida o solución mágica que derrote el extravío, "una forma de mirar no es alternativa a la otra" (Oliva Mendoza, 2002: 90): "sin saber de qué o por qué tenía que calmarla". Lucho únicamente puede ver con luminosa certeza la soledad de Dina, estado que clama por la protección, comprensión y apoyo del otro: 
— No llores — dijo Lucho—. No vamos a ganar nada si te ponés a Llorar.

- No quiero llorar dijo - Dina-. Pero nunca había podido hablar con alguien así, después de. Nadie me cree, nadie puede creerme, usted mismo no me cree, solamente es bueno y no quiere hacerme daño.

- Ahora te creo - dijo Lucho-. Hasta hace dos minutos yo era como los otros. A lo mejor deberías reírte en vez de llorar. -Ya ve - dijo Dina, cerrando los ojos-. Ya ve que es inútil. Tampoco usted, aunque lo diga, aunque lo crea. Es demasiado idiota. (Cortázar, 1998: 112).

La médula de ese llanto feliz, de esa felicidad de amor es la disipación de la soledad, porque es de alguna forma encontrar un oasis de alivio que en el mundo árido de los otros es reemplazada por la vejatoria incomprensión. "Ahora te creo [...]. Hasta hace dos minutos yo era como los otros. A lo mejor deberías reírte en vez de llorar", y de hecho, su llanto entraña alegría por el encuentro: "No quiero llorar [...]. Pero nunca había podido hablar con alguien así, después de [...]”. La adversativa seguida del adverbio de frecuencia opone el reiterado dolor provocado por los otros al momento singular del encuentro con Lucho, el cual se muestra tan especial que es casi increíble por su mismo carácter extraño: "Ya ve — dijo Dina, cerrando los ojos-. Ya ve que es inútil. Tampoco usted, aunque lo diga, aunque lo crea. Es demasiado idiota". Luego, la semilla de la derrota echa raíces como un vaticinio (prolepsis) de la expulsión. La respuesta de Dina enuncia la fragilidad del encuentro, "aunque lo crea". La adversativa cuestiona las promesas que puedan ofrecer el vínculo emotivo; al fin y al cabo, como ella lo dice, "es demasiado idiota" su padecimiento y "es tan lógico. Tan lógico" (110) no creerle. Sin embargo, Lucho atraviesa la barrera de lo común, "hasta hace dos minutos yo era como los otros", ofreciendo el reflejo en su mirada como una alternativa: "hubiéramos podido encontrar juntos, [...], Dina todavía podemos encontrar la vela". La vela símbolo de la salida debido a su carácter de portadora de luz. La secuencia presenta el símbolo como una imagen de los objetivos de la orientación en el laberinto, lo que se llamaría el "jardín central" donde aguarda el Minotauro o la cancelación del atrapamiento trágico.

Su propuesta conciliatoria del otro afronta decidida el posible extravío en el laberinto o las penosas confusiones implicadas en tal odisea hacia el centro, "qué mano buscarás, Dina, qué cara arañarás". El intolerable acto de la agresión del gato (rechazo al no reduccionismo sexual del vínculo amoroso), soportándose estoicamente mientras se sigue ofreciendo, porque se cree necesario para brin- 
dar alivio y seguridad, y la satisfacción sexual no impedida, porque es derecho legítimo del ser, ambos intentándose equilibrar en la balanza del reconocimiento de Dina como objeto amado: "no importa que siempre haya sido así pero abrime, éramos otra cosa". Ese ser-otra-cosa trasciende, por un lado, el frío e imposible esencialismo de La Voz; por otro, el inmanentismo desproporcionado de La No-voz, y además de ello, la falta de respuestas propia del árido mundo de los otros. Es por ello que "no importa que siempre haya sido así", sin promesas más visibles que el arduo disputar entre el gato y la esencia, ya que en la tibieza nocturna del amor ambas porciones pueden hallar lugar.

Pero el sello de la derrota ya estaba puesto. Los personajes cortazarianos sufren de atrofia crónica para el amor -recuérdese al mayor de los paralíticos, Horacio Oliveira-. La expulsión del otro (Lucho) obedece a un principio narratológico cortazariano: las formas del amor son siempre una invasión amenazante a la zona sagrada, y ante ella se debe reaccionar.

Jitrik define zona sagrada como "pasaje de interioridad profundamente resguardada, tal vez oprimida, y al acecho hacia el exterior, es una 'zona sagrada' que termina por resplandecer y que se generaliza al transmitirse cubriendo todo el vivir del que la contenía" (1969: 19). Es sencillamente contenido interno que singulariza al personaje y lo convierte en un "apestado, un intocable, un privilegiado" frente a la zona de los otros, para quienes no existe ninguna posibilidad realizativa dentro de la zona sagrada. Vive así, el personaje, el máximo de los aislamientos, la soledad. Ejemplos ilustrativos de ello: Delia Mañara ("Circe") con su sadismo artístico; Horacio Oliveira, con su búsqueda de absoluto, su inconformidad esquizo; la paraplejia de Leticia, escondida tras el juego de las estatuas ("Final del juego").

Al no encontrar comprensión en el mundo de los otros, explica Jitrik, el personaje busca "entonces un igual" -sería mejor decir un islote de seguridad, El Otro-, renunciando de inmediato a la comprensión de la mayoría en un acto desafiante de "orgullosa culpabilidad". En el contexto de "Cuello de gatito negro" la conformación del "grupo" no es salida y ni remotamente el encuentro de un igual. Como toda forma de amor cortazariano, la vinculación de Lucho es percibida como ente desestabilizador de la zona sagrada específica de Dina (la escisión de su yo). En este punto, creo, hace presencia el complejo de Ariana.

Ariana conoce la solución al problema del atrapamiento laberíntico y está capacitada para exorcizar al monstruo, metiéndolo den- 
tro de sí: tiene el amor. Pero toda ella es titubeo, miedo a las galerías del enigma dedálico, por eso retrocede y permanece del lado del muro donde su prisión se eterniza. En el ensayo Las transformaciones del yo, su autor, Filer Malva, explora las formas en que el yo en la obra de Cortázar se desdobla o afronta a su doppelganger, sufriendo un proceso de confusión y perdiendo de alguna forma la noción de identidad propia (1972: 263-276). El autor concluye por afirmar que en la obra de Cortázar existe un conflicto entre la noción occidental del yo individual y otra inspirada, según él, en el Zen, de yo ubicuo, resultante de la disposición del primero a perder sus fronteras y verse "mágicamente expandido" o indiferenciado de la otredad. Al conflicto lo alimenta la transitoriedad de la ubicuidad, puesto que "se le niega finalmente al yo la posibilidad de vivir en los dos planos (el yo y el no-yo)" (Malva, 1972: 274), generando el hecho de que los personajes cortazarianos "deben elegir entre aniquilar el doppelganger, dejarse aniquilar por él, o destruirse, física o moralmente, como ocurre en Rayuela" (275). Desde el punto de vista que rige el presente trabajo, ese miedo a la pérdida de las fronteras de la individualidad comparte semejanzas con el miedo de Ariana, pero no bajo las mismas coordenadas de las piezas tratadas en Las transformaciones del yo. Lo comprometido es la seguridad que representa la zona sagrada. Toda solución destructiva del laberinto, pese a implicar el final del confinamiento, supone la invalidación de la lógica de la zona, la cual, pese a su carácter esencialmente molesto,

[...] se lleva alguien adentro hasta determinado momento sin saberlo pero a partir de un instante se lo sabe, no hay más remedio; ese instante marca el comienzo de un sentimiento de incomodidad, una gravidez connotada por la extrañeza: después de todo vomitar un conejito ha de ser un episodio no demasiado natural; sin embargo, la incomodidad, como en la gravidez, da paso a un nacimiento y aquello que se presentaba en germen, provocando incomodidad, gana terreno, crece y triunfa sobre aquel que lo contenía [El destacado es nuestro]: son diez, once conejitos, es la miserable que pasa a ser Alina Reyes, es la alegría convulsiva de Delia Mañara al darle excitada el bombón con las cucarachas al tercer novio, [...]. (Jitrik, 1969: 19)

se experimenta como la única realidad autentica o piso firme que ha mantenido al personaje explicado ante sí mismo. Piénsese en el protagonista de "Manuscrito hallado en un bolsillo" rechazando la posibilidad de encontrar amor fuera de las estrictas reglas del juego, porque desde su zona esquizo se percibe a sí mismo como la única entidad con visión, y en tal estado de cosas, aceptar a Marie-Claude, 
sin que el juego la avale, equivaldría a negar toda la estructura de su visión esquizoide del mundo, y por ende, enfrentar la crisis existencial del derrumbe de la imagen de realidad en la cual se movía. Al fin y al cabo, aun cuando la zona empuje a lanzarse del piso alto de un edificio residencial para morir junto a los conejitos vomitados, o impida a Leticia conocer al muchacho que se interesó en ella, como dice Cortázar, el hombre es el animal que se acostumbra hasta no estar acostumbrado.

Esta costumbre no tiene nada que ver con una resolución conciente. El personaje está positivamente impedido. Para el caso de Dina, en "Cuello de gatito negro", la lógica de la escisión coloca freno a la posible aceptación del Minotauro, la cual amenaza como una opción bajo la intervención del amor nocturno del otro:

- Ahora te creo - dijo Lucho-. Hasta hace dos minutos yo era como los otros. A lo mejor deberías reírte en vez de llorar. -Ya ve —dijo Dina, cerrando los ojos-. Ya ve que es inútil. Tampoco usted aunque lo diga, aunque lo crea. Es demasiado idiota. (112).

La invitación de Lucho no halla eco en la chica. Desde ella, la derrota se exhibe como un a priori: "aunque lo crea". La barrera es clara, la doble servidumbre del yo -obediencia a la autoridad superyoica, permisión a la sed infinita del 'réprobo'- percibe un factor más de justificación para la preservación de la zona sagrada. De alguna forma, Lucho actualiza en la otredad la doble servidumbre, reflejándola en sí mismo, porque la propuesta conciliatoria de su nocturnidad es encausada precisamente para halagar a la identidad (La Voz), mientras se satisface a la instintividad (La No-voz). El doble fracaso ocurre completando el ciclo de perpetuación de la zona con la expulsión de Lucho: “[...] tendré que decirles que estás ahí tirada, que traigan otra frazada, que echen la puerta abajo, que te cuiden y te protejan porque yo ya no estaré ahí, [...]" (1992: 116).

Ya se habrá notado. El complejo de Ariana en Dina depende de la capacidad de la zona para autorreafirmarse, y esta capacidad de la profunda necesidad de mantener el "simulacro", evitando el derrumbe existencial y emocional conllevado por la angustia. El gran desencadenador ya se conoce, la autoridad con todo su peso superyoico. En esencia, todo depende de una primitiva renuencia a admitir el Minotauro, tal como sucede con Minos y Teseo, y los contenidos de la ontología platónico-cartesiana son el tejido de sostén de la misma (la represión de la instintividad), además de responsable indirecto 
de la existencia de la autonomía corporal y su contradiscurso (la visión erótica). La "monstruosa discrepancia", "la doble condición animal" de la que habla el Minotauro es ser corpóreo, ser momentáneo, ser inmanente, ser sexual. Entre la autodefinición y la anulación hay una derrota compartida. Allí habita la invulnerabilidad del laberinto: Dina no puede renunciar al doble fracaso; no saberse el monstruo es igual a no serlo.

\section{Conclusión}

¿Qué definición ontológica de lo humano puede extraerse de la existencia trágica de Dina? A ojos de una lectura desprevenida, el lector admitiría los discursos de La Voz. Pensaría entonces que el ser de lo humano está en la inmaterialidad y la perfección de la idea. Hablaría de alma, de trascendencia, de autenticidad y del asco que despierta el cuerpo. Abrasaría la estructura de mediación más determinante del cuento y la tradición discursiva más influyente de la historia occidental. Sin embargo, la crisis habita en el corazón de esa supuesta verdad. En Dina hay una línea de ambigüedad donde La Voz se quiebra; es el lugar de la segunda lectura: La No-voz 'habla' a la sombra, deconstruyendo el discurso esencialista. A partir de allí, el lector duda, pero no por eso sería capaz de adscribir el ser del personaje a esta nueva ontología, y mucho menos, en la antigua. Entre La voz y La No-voz, Dina se fragmenta, su ser es sombra esquiva. Lo único visible es la tensión trágica, actualizada por el fracaso de ambas entidades (La Voz y La No-voz). Debido a ello la disputa carece de solución, y Dina seguirá atrapada en su laberinto. Nada más se admite dentro del juego trágico de la escisión del yo. Por ello la propuesta nocturna de Lucho (el amor) no prospera. La conciliación de los opuestos está descartada, porque eufemizar ${ }^{4}$ implica renunciar a la doble servidumbre del yo (satisfacer al ello mientras que se obedece al súper yo). En esta lógica ambigua naufraga toda pretensión de definir ontológicamente al personaje. Dina es una representación del maniqueo espíritu occidental, introyectando complacido el rígido trascendentalismo ascético de Platón y Descartes, mientras que a la sombra se entrega al éxtasis de una filosofía corporal, sólo para que a la luz del día le encaje bien en la espalda la autoflagelación, sintiéndose lo suficientemente sucia.

\footnotetext{
${ }^{4}$ Proceso mediante el cual el régimen nocturno dulcifica las formas del régimen de los rostros del tiempo, asimilándolas positivadas dentro de su estructura.
} 


\section{Bibliografía}

American Psiquiatric Association. D.S.M. IVTR. (2002). Manual de diagnóstico y estadístico de los trastornos mentales: Trastorno de la identidad disociativo y Trastorno histriónico de la personalidad. Barcelona: Masson.

Bal, Mieke. (1990). Teoría de la narrativa. Madrid: Cátedra. $3^{\S}$. ed. Trad. Javier Franco.

Cortázar, Julio. (1998). “Cuello de gatito negro” (Octaedro) en: Cuentos completos, Vol. 2. Madrid: Alfaguara. 9a. ed, pp. 43-116.

. (1983). Último round: /que sepa abrir la para ir ajugar. Bogotá: Siglo XXI.

. (1992). Los reyes. México D.F.: Alfaguara.

- (1995). Bestiario. Argentina: Taurus. (1996). Rayuela. Madrid: Cátedra.

Cros, Edmond. (1986). Literatura, ideología y sociedad. Madrid: Gredos (trad. Soledad García Mouton).

Descartes, René. (2005). Discurso del método y Meditaciones metafísicas. Madrid: Espasa Calpe. Trad. Manuel García Morente.

Durand, Gilbert. (1981). Las estructuras antropológicas de lo imaginario. Madrid: Taurus.

Freud, Sigmund. (1974). El malestar en la cultura; Inhibición, síntoma y angustia; La negación: la escisión del "yo" en el proceso de defensa; El "yo" y el "ello"; Los dos principios del funcionamiento mental, en: Obras completas, Vols. 5, 7, 8 y 9. Madrid: Biblioteca Nueva. Trad. Luis López-Ballesteros y de Torres.

Harss, Luis. (1969). Los Nuestros: Julio Cortázar o la cachetada metafísica. Buenos Aires: Suramericana. $3^{\mathrm{a}}$. ed.

Jitrik, Noé. (1969). "Notas sobre la 'la zona sagrada' y el mundo de los 'otros'” En: Bestiario de Julio Cortázar, en Pérez, Carlos, La vuelta a Cortázar en nueve ensayos. Buenos Aires: Talleres gráficos, Talgraf.

Kolb, Lawrence C. (1976). Psiquiatría clínica moderna: Las neurosis. México D.F.: La Prensa Médica Mexicana.

Laing, Ronald D. (1994). El yo dividido. Bogotá: F. C. E. Ttrad. Francisco González Aramburu.

Malva E., Filer. (1972). “Las transformaciones del yo”. En: Giacoman, Helmy, Homenaje a Julio Cortázar. Variaciones interpretativas en torno a su obra. Madrid: Anaya.

Marcuse, Herbert. (1989). Eros y civilización. Barcelona: Ariel. 2§. ed. Trad. Juan García Ponce.

Nietzsche, Friedich. (1981). El nacimiento de la tragedia: La visión dionisiaca del mundo. Madrid: Alianza.

Oliva Mendoza, Carlos. (2002). Deseo y mirada del laberinto, Julio Cortázar y la poética de Rayuela. México D.F.: CONALCULTA. 
Platón. (1996). “Fedón o del alma” y "Simposio (Banquete) o de la erótica”. México D.F.: Porrúa.

Thompson, Clara \& Mulliahy, Patrick. (1992). El psicoanálisis. México: F. C. E. Vallejo Ruiloba, J. (2002). "Histeria” y “Neurosis". En Vallejo Ruiloba, J., Introducción a la psicopatología y la psiquiatría. Barcelona: Masson. 5 . Ed. 